The main objective of the present study was to find out the variation of taper with different ages for Tectona grandis L. f. (teak). For this reason, three teak plantations of 22, 27 and 35 years of age were selected from the Block 01 in Kotagoda plantation, Ampara Forest Division. Selection of these three plantations from a single Block was done to minimise the effect of the site quality on tree growth. Data were collected from randomly laid out 14 circular plots of 0.05 ha. The trees in sample plots were measured for dbh, total height and sectional diameters at $5 \mathrm{~m}$ and $10 \mathrm{~m}$ along the stem.

In order to estimate the taper variation, the equation developed by Kozak et al (1969) for Douglas fir in Western Colombia was used. This equation is given below and it is considered as one of the best models developed to estimate the upper stem tree diameters.

$d^{2} / d b h^{2}=b_{0}+b_{1}(h / H)+b_{2}\left(h^{2} / H^{2}\right)$;

where $d=$ diameter at height $h$ and

$H=$ total height

At the first stage, the data were fitted to the selected equation separately for each age and the regression parameters were estimated separately without changing the basic structure of the original equation.

It was observed that the parameter $b_{1 \prime}$ and $b_{2}$ were positive values and increased from age 22 to 27 and then decreased from that to age 35 . The parameter $b$, was a negative value which decreased from age 22 to 27 and then increased from that to age 35 .

When the results were examined further, it was observed that the taper is decreasing with the age proving that the teak tree stems become more conical with the age, i.e., the diameter difference increases with age for a fixed length along the stem.

\title{
003 \\ Predicting the optimal rotation length of Teak plantations using a simulation model
}

L H P Gunaratne and T N Subramanium

Department of Agricultural Economics and Business Management, University of Peradeniya, Sri Lanka.

The traditional problem in Forest Economics has been mainly dealt with the estimation of optimal rotation length for sustainable management. However, given the limitation of the availability of time series data on growth and management in forest plantations in Sri Lanka, such estimations are not feasible. Against this background, this study attempted to develop a simulation model and predict rotational interval of teak plantation under different management conditions.

A field survey was conducted to identify the plantation related parameters in the Kurunegala District. Meantime, a simulation model was developed with Microsoft Visual Basic and Microsoft Excel using the equations specified in the Teak Management Plan (1997) to supplement the field data. The past data obtained from the Forest Department was used to parameterize the model. Using the age and the height of a plantation at a particular time, the model was capable of predicting the plantation related parameters such as $\mathrm{dbh}$ and timber volume over the time.

According to the values predicted by the simulation model, four different categories were identified based on the site index, which represents the level of growth of a stand. Rotational interval was estimated using the Faustman rotational model at different discount rates. Thereby it was estimated that the rotational intervals for the four categories at discount rates $10 \%, 15 \%$ and $20 \%$ as 19.17 and 15 years respectively. The internal rate of return obtained through the simulation was above the market rate of $12 \%$. Though the model yielded shorter rotational intervals than the present field values, the approach could be used in future with more reliable field data.

Proceedings of the International Forestry and Environment Symposium 2006 of the

Department of Forestry and Environmental Science. University of Sri Jayewardenepura, Sri Lanka 